\title{
ACCOUNTING INFORMATION SYSTEMS AND KNOWLEDGE MANAGEMENT
}

\author{
Mohammed Khaled Aljarallah \\ Ph.D. Student of Public Administration at King Saud University, Saudi Arabia
}

\begin{abstract}
The use of accounting information systems (AIS) has evolved over the years as organizations aim at getting the best out of their resources. The Aim of this paperlooks into accounting information system in general and goes more specifically into how QuickBooks has evolved over the years. The different abilities it has, and how internal controls can be used to enhance data and system security. The main subject represented in knowing the most important requirements of successful accounting information systems, and knowing what difficulties the organization faces when using accounting information systems
\end{abstract}

\section{KEYWORDS}

Information system, Accounting, Knowledge management.

\section{INTRODUCTION}

According to Ibrahim, Ali, \&Besar (2020), accounting information systems (AIS) entail the structures that are used by businesses in the collection, storage, management, processing, and retrieval as well as reporting of the organization's financial information and data. The invention and subsequent use of accounting information systems (AIS) by trained accountants has helped enhance work efficiency and improved accuracy in financial transactions and also keeping of records. At the same time, AIS makes data easily available and accessible to authorized individuals.

Knowledge management, on the other hand, entails systematically managing the knowledge assets within an organization to purposely create value as well as meet the strategic and tactical requirements. The process includes different strategies, initiatives, systems and processes which enhance and sustain creating, storing, assessing, sharing and refining knowledge.

Knowledge management and accounting information systems are compatible and all aim at ensuring that data and information are created and shared as per the set standards [1]

\section{HISTORY AND DEVELOPMENT OF ACCOUNTING INFORMATION SYSTEMS}

Accounting information systems have evolved with the growth and development of technology, more so the use of the internet. The history of accounting information systems can be divided into three major phases: the 1990s era, the 2000s era and 2010 up to date. During the 90 s era, which was popularly known as 'the windows age', the applications at the time were strong, but could only handle the basic operations in accounting.

The traditional accounting operations mainly focused on financial reporting and bookkeeping and eventually preparing and presenting financial statements. At such a time, the main reason for 
International Journal of Managing Public Sector Information and Communication Technologies (IJMPICT) Vol. 11, No.2/3, September 2020

accounting information was to give the users of accounting information, the data required to understand the financial position and direction of the organization. This objective was attained through the use of small systems created purposely to support reporting of financial information [2].

After accounting operations were automated, technology improved, changing further into the automation of document management and collection, through the creation of methods like einvoicing, e-payments as well as e-archiving. Technology in this regard responded well to the demands in the market, with accounting software that could be customized to meet the demands and needs of every organization, matching their profile and operational practices. Transparency in accounting improved as transactions could be tracked to the source, hence reduced cases of fund embezzlement through accounting systems.

\section{USE OF InTERnal Controls to CONTAIn OCCUPATIONAL FraUd}

According to Steckel (2011), occupational fraud entails using an individual's occupation to enrich oneself through deliberately misapplying and misusing the resources in the organization. In many cases, it is the employees who violate the trust that they have been bestowed upon by their employers and use their position to gain wrongly. However, as per Steckel organizations can create internal controls to ensure that the majority if not all loopholes have been sealed. Internal control is a process impacted by a firm's management, directors and other stakeholders, meant to offer possible assurance on the attainment of organization objectives

Methods for attaining strong internal controls in different organizations are:

\subsection{Business Laws and Regulations on Information Systems Use}

Any organization operating in a country with laws must abide by the set rules and regulations about business operations. Steckel (2011) notes that besides making sure of reliable financial records and safeguarded assets, any organization using AIS should ensure that their systems adhere to the regulatory requirements. These regulations are mandated by the (PCI) Payment Card Industry, as provided by the PCI council (2010). At the same time, here has been the enactment of data breach notification laws over the past few years to ensure that information systems are used appropriately without breaching any kind of individual or organizational law. The laws state that organizations are required to ensure that they inform that customer if by any chance, a breach to the organization or customer data has been experienced.

\subsection{Finding Software Features Related to Internal Control}

There is some literature on the software security built-in features exist, discussing the importance of using the features and the way they should be used to enhance safety for the accounting systems. Intuit, the developer of QuickBooks published a manual on how small businesses can use internal controls to decrease the potential risks of fraud. Although the manual discusses how internal controls are used in business, it mainly discusses how they should be implemented. This shows that implementation is the most important aspect of internal controls as that determines the level of success.

Moreover, Steckel (2011) indicates that usernames and passwords are part of the internal controls. However, even though there are built-in features of internal control within QuickBooks, there is no empirical research done to determine whether the features are used well in practice. 
International Journal of Managing Public Sector Information and Communication Technologies (IJMPICT) Vol. 11, No.2/3, September 2020

However, existing literature offers a unique opportunity and experience in research to contribute to the accounting field.

\subsection{Security Level Maintained by Small Business on Information Through Internal Controls}

To determine this, Steckel conducted an online survey, listing 10 most important and basic features to be tested. The research featured a total of 200 organizations, whereby only 36 responded (18\% response rate). However, 21 of the 36 organizations that responded indicated to have used one version of QuickBooks accounting software. The majority of the organizations indicated that they use a desktop version, with only one indicating to be using an online version. This meant that the researcher could not come to a complete conclusion based on a response from only one online user. The researcher also examined whether the users utilized usernames and passwords for the desktop version, and a total of 30\% indicated that they do not have usernames or desktop, but $70 \%$ indicated that they have set usernames and passwords as extra security measures. This shows that not all the organizations and users of QuickBooks make use of the available internal control measures and features within their systems.

The Steckel's study adds new knowledge to the current increasing trend of organizations going online to operate remotely through the use of procured online systems such as QuickBooks. At the same time, there is new knowledge and literature added to accounting systems security. The knowledge is important because there are increasing cases of attacks on organization systems from hackers, who steal information, alter information or even channel funds from the organization accounts to their accounts without being noticed.

\section{IMPORTANCE OF INFORMATION SYSTEM AND TECHNOLOGY FROM SOCIOTECHNICAL ASPECT}

It is important to project information systems as well as technology in a sociotechnical approach. A sociotechnical system is the one that has a social organization and material technology as well. This aspect of the system has come up with many changes that have a positive impact. Employees work is based on unity and not in segmented tasks. This effort of unity in accomplishing goals has led to a conducive working environment [3]. Employees are now doing a perfect work while interacting with fellow colleagues. While the effect of standardization and formality has reduced, workers are now expected to portray deep knowledge and understanding of their work. Through this, there is improvement in opportunities for making skills better.

There is not only a rise in the level of satisfaction in employees, but also an increase in the level of production. These levels as mentioned are considered as famous products in these aspects of social-technicality. They are also referred to as autonomous groups. These groups have not yet been applied and accepted all over the world, but are proven to have some efficiency. Another importance of this sociotechnical aspect in information systems and technology is that many managers who have a high position in management can be controlled partially within the groups. This implies that less amount of money is required for managers who are highly educated and with higher skills which are well paid.

Not much money will be used when dealing with these scenarios. The most important worth of this system is that, it touches those who gain the profit made and those that create that profit. The system has been made to meet the needs of employees, that is, social needs and psychological needs and that has risen the profit of the work done and put it together with technology. This increase in a firm's business cannot be successful without this information system in meeting 
their needs. It is important to view this technology from a socio-technological aspect because technology is like a tool. This aspect has inspired many researchers who created an influence in their associations were said to be influential researchers in initiating sociotechnical research in information systems. They were concerned with information systems, although they had a limit in engineering approaches.

\section{TyPES OF INFORMATION SYSTEM VALUABLE TO AN ORGANIZATION}

Information systems can be viewed as formal organizational systems aimed to collect, process store and distribute information. Computer information systems are usually composed of computers, infrastructure and people. Information systems can be broadly categorized into four main categories. These are Transaction processing systems (TPS) which are used in the data collection and storage of incoming and outgoing transactions in an organization; decision-support systems (DSS) which are used to give support during the determination, judgement and action to be taken in an organization. [4] They analyze the a lot of data and produce important information that is useful to the organization during the decision-making process to provide solutions to the problems; Management information system (MIS) which is a database where financial information which is organized and programmed to produce reports regularly on the operation of the organization on each level of management in the organization and executive support systems which are also referred to as the executive information systems are management support systems support the senior executive information and facilitate decision making .[5] They enable the senior executive to access the external and internal information that is related to the attainment of the organization goals easily.

Transaction processing system is used in the operational level systems, while management systems use MIS and DSSs and final the executive systems are involving strategic level systems. Transactions systems are mainly used in the collection of data, storage of both incoming and outgoing transactions within the business [6]. The system enables data transaction in the database system that monitors how the transaction programs are running. They are very essential through the performance of the business, data integrity, growth and availability. The systems are integrated in the selling of items on online market since they allow time delay between when the item was sold and the actual time when the item was sold. TPS is the most important systems and also the most valuable in any organization [4]. This is due to the fact that this level is involved with more work on a daily basis than the other levels in the organization. The systems record the daily routine transactions that take place in the operation of the organization daily. Transaction processing systems also collect data and combine it into various forms that enable the organization to become more organized and orderly leading to its success. The systems are the best when they provide the users with the required high quality and useful information when it required for the running of the organization.

\section{IMPACT OF NEW INFORMATION SYSTEMS}

Information systems play a very important role in the success of an organization or organization. In the current era its where digital economics, globalization and digital organization is taking place, it's no longer about if an organization should have an information system but it's about whether the organization has an information system it's about if the information system in the organization is effective. [7] Therefore, the success of the information system is a huge determinant/ has huge influence on the success of the organization. Implementation of a new system of an organization will affect the organizations culture and politics in different ways. 
The culture of organizations is mostly unassailable, bedrock assumption by its members that define the goals and their products. The culture is the assumption of which products the organization should produce and how they should produce, when and where they should be produced. The actual business values are intertwined with the organization Culture of the firm [8]. New information system tries to implement and accommodate the culture, however there are some changes which are made for successful implementation of the system. Information systems affect the culture based on the information quality, service quality, system user satisfaction and usefulness. The quality of the information that the new system provides has a huge impact on the culture of the organization. The information provided is used to make decisions which determine the success of the organization [9]. High quality information provided to the superior will enable them to make the appropriate decisions which will enable the organization to attain its goals. In most organizations, the superior is assumed to know it all. If the system provides them with information that leads them to making poor judgment calls will affect the culture negatively as the inferior will start viewing them from a different perspective. Information system also has an impact on the organizational politics. Organization politics refers to the different positions that people in an organization occupy based on concerns, perspectives and specialties.

Based on those aspects they develop a natural viewpoint on matters regarding rewards, punishments and resources allocation. The difference concerns the managers and the employees.

New information system in organizations will have several impacts on its functionality. The cultural and political impacts are some of the most common witnessed impacts of new information system. Before development and implementation of a new system is done, its recommend that the factors are considered to determine how the system will have more positive cultural and political influence on the organization.

\section{THEORIES ON THE IMPACT OF ORGANIZATION SYSTEM}

The difference between the economic theories and behavioral theories in relation to information and technology can be analyzed and discussed based on their view and approach to information technology[10].

From the economic theory information systems can be viewed as a factor of production that can be easily substituted with capital and labor. Information systems enable automation of production processes; less labor and capital in order to produce a specified output. However, in behavioral theory, information systems can be defined as a group of rights; privileges; obligations and responsibilities which end up balancing within a given period of time through conflict and conflict resolution. The theory focus on how the information system influences the inner working environment of the organization.

The transaction cost theory which is based on the notion that the firm instead of making products for itself, incurs transaction costs when acquiring goods in the marketplace. Traditionally, organizations find ways to lower their transaction costs through getting bigger, hiring more employees, small-organization takeovers; horizontal and vertical integration therefore information systems help the firms to minimize the transaction costs. They help the organization in reducing in size with the same output production [11]. On the other hand the behavioral researchers consider the information system influence on the decision making thus reducing the information acquisition cost and distribution cost. Information systems can eliminate the middle level managers and their support clerical by sending the information directly from the senior manager to the lower-level operation units directly. This also enables the organization to act as a virtual firm since the geographical limitation is eliminated. 
Although the economic theory view information systems as a factor of production while the behavioral theories view the information systems in regarding to their influence on the behavior of people in carrying out their operations, both of them indicate that information system has a positive impact on the organization. There for firms are encouraged to adopt information systems on their production process and decision making.

\section{SUCCESS FACTORS OF AIS SOLUTIONS}

\subsection{Service Quality}

For accounting information systems succeed in organizations, the services that they deliver and those that they offer should of high quality. The systems are normally put in place to enhance better performance through automated service delivery. Thus, the quality of service that they deliver to the organization is a great determinant of how successful the accounting information system will be in the organization. At the same time, AISs are normally connected to other systems within the organization to enhance better resource utilization and better service delivery. As such, the quality of service and support provided from the other systems will determine how successful the accounting information systems will be in the organization [12].

\subsection{Information Quality}

Information is an important aspect of the success of any system's operations. As such, the information provided about certain data determines how the data will be applied and interpreted by AIS, hence success or failure. Accounting information systems are always expected to work using high-quality information. As such, with high-quality information provided, accounting information systems are likely to run to the expected standards and produce high-quality results in the end. At the same time, poor quality information will translate to poor system operations and failure, hence inability to achieve the set targets and standards of performance [13].

\subsection{Data Quality}

Data is the most important component of any database that involves storage and analysis of data, hence determining the importance of such a database [14] Thus, it is always important to ensure that the quality of data stored in the database and the quality of data used in processing is always high to enhance better system operations. Accounting information systems depend on the data presented to do analysis and present reports that are used for decision-making. If in any case wrong data is presented and used in the analysis, then all the subsequent results and decisions made out of the data will be wrong. This will drive the organization in a wrong direction, hence create an image of a failed accounting system, which could have been avoided if the right data was used in the analysis and making of decisions [13].

\subsection{System Quality}

The quality of the accounting information system is also an important factor to consider when determining the success of the AIS. There are many vendors of AIS software in the markets and it is up to the organization to work towards ensuring that they select the best in terms of quality. Thus, proper vetting of vendors should be done to ensure that the best quality is selected in this regard. When looking into the system quality, this is done in terms of system security, the ability to withstand challenging times and downtimes, and system availability. System security is an important aspect to consider because the data have been always important for organizations and ensuring that the systems are protected against any form of harm brought to them. System 
International Journal of Managing Public Sector Information and Communication Technologies (IJMPICT) Vol. 11, No.2/3, September 2020

downtimes can be stressing to users in systems, hence having systems that can withstand any possible downtimes and that can also handle large amounts of data without crumbling is a measure of a good quality system [12].

\section{Conclusion}

Accounting information systems have become a critical part of organizational operations across different industries. It has become essential that the majority of the accounting tasks done by people in the past be handled by automated systems.

- These systems have a wide range of capabilities, including coordinating with all departments and using the data available from the departments. AISs have also ensured that there is better accountability as no individual decisions are made without the system keeping the record. This has reduced the possible cases and instances of theft within organizations and enhanced better accountability [15].

- With accounting information systems that well designed to meet organizational objectives, all stakeholders within the organization with access to data can access the system and use the same information at the same time, without having to go through a lengthy process in the end.

- Organizations are faced with the dilemma of either purchasing one or developing an accounting information system that suits their business needs.

O One of the main factors is the cost of either production or getting the system off-the-self. Many at times, picking a system off-the-self is cheaper because they are developed in large numbers and tend to be uniform in operations depending on the industry or organization that one operates. However, developing a customized system is a bit challenging, hence costly to develop [16]. If an organization has an existing system that is already operating, then it might consider developing a system that conforms to their needs and requirements.

- The time available will be crucial in determining the level of quality required in the new system to be developed, since having enough time will lead to a better system being developed, and having less time might make the system developers rush and not manage to attain the expected levels of the outcome.

- The main determinant should be the level of security that the system can assure the organization in terms of keeping the customer data and the data of other stakeholders safe.

- With technological developments and the invention of cloud computing has created a new dimension. Organizations like QuickBooks have taken advantage of the new developments in technology and captured a large part of the market share.

- An accounting information system to be successful.

- There must be sufficient IT infrastructure. In this regard, the infrastructure is mostly made up of computer hardware used in operating the accounting system; there must also be an operating system that will be used in controlling the operating system and other related software. 
International Journal of Managing Public Sector Information and Communication Technologies (IJMPICT) Vol. 11, No.2/3, September 2020

- Additionally, to cost, some of the factors that must be considered when implementing an accounting information system include scalability and the capacity for storage.

- Compatibility is an issue that should always be considered when choosing hardware for AIS because systems are meant to run on hardware that can sustain them. One of the means that businesses can meet the requirements of software and hardware compatibility is through the purchase of a turnkey system which entails both the software and hardware required by the business.

- A good accounting information system should have a plan for use, maintenance, service, upgrading and replacing of components within the hardware system. This is to ensure that organization data is safeguarded and any sensitive data is discarded to avoid any possibility of leaking sensitive data to outside parties [17].

- An accounting information system must have internal controls to help them protect against unauthorized access in computers and also limit access to those who are authorized to ensure that data is not compromised. Internal controls must also help to prevent any unauthorized access of files by people who have only been given privileges to just access some parts of the system.

\section{REFERENCES}

[1] Ibrahim, F., Ali, D. N. H., \& Besar, N. S. A, "Accounting Information Systems (AIS) in SMEs: Towards an integrated Framework," international Journal of Asian Business and Information Management (IJABIM), pp. 51-61, 2010.

[2] Hingorani, K., \& McNeal, B. , "Using Quickbooks Online Plus for Enhancing Learning Of ERP Concepts: A Case Study," issue in information system, pp. 132-139, 2018.

[3] McLeod, L., \& Doolin, B. , "Information systems development as situated socio-technical change: a process approach," EUPOREAN JOURNAL OF INFORMATION SYSTEM, pp. 176-191, 2012.

[4] A. B. Qehaja, "ResearchGate," June 2013. [Online]. Available: https://www.researchgate.net/.

[5] T. Lucey, Management of information systems 9TH Edition, London: Thomson Learning, 2005.

[6] D. K. a. R. Hatch, Business Information systems 5th Edition, New York: Mc Grow Hill, 2000.

[7] M. I. System, "Managing the Digital firm," 2006. [Online]. Available: https://paginas.fe.up.pt/ acbrito/laudon/ch3/chpt3-1main.htm.

[8] I. M. Romi, " Organization Culture Impact on Information Systems Success," April 2011. [Online]. Available:

https://www.researchgate.net/publication/233857776_Organizational_Culture_Impact_on_Informatio n_Systems_Success.

[9] Ismail M. Romi,Ibrahim A. AwadManal Elkordy, "A Model of Organizational Politics Impact on Information Systems Success," 15 December 2009. [Online]. Available: https://link.springer.com/chapter/10.1007/978-90-481-3660-5_19.

[10] Kenneth C. Laoudon and Jane P. Laudon, Management Information system, New Jersey: Printice Hall, 2007.

[11] L. M. Lovata, "JSTOR," JOURNAL ARTICLE Behavioral Theories Relating to the Design of Information Systems, pp. 145- 147, 2000.

[12] Davis, J. T., Ramamoorti, S., \& Krull Jr, G. W. , "Understanding, Evaluating, and Monitoring Internal Control Systems: A Case and Spreadsheet Based Pedagogical Approach," AIS educator journal, pp. 59-61, 2017.

[13] Ganyam, A. I., \& Ivungu, J. A, "Effect of accounting information system on financial performance of firms: A review of literature," journal of business and managmenet, pp. 39-49, 2019.

[14] Hla, D., \& Teru, S. P, "Efficiency of Accounting Information System and Performance Measures," international journal of multidisciplinary and current research, pp. 976-984, 2015.

[15] S. N. Soudani, "The usefulness of an accounting information system for effective organizational performance," international journal of economic and finance, pp. 136-145, 2012. 
International Journal of Managing Public Sector Information and Communication Technologies (IJMPICT)

Vol. 11, No.2/3, September 2020

[16] N. Mndzebele, "The usage of accounting information systems for effective internal controls in the hotels," international jouranl of advanced comupter technology, pp. 1-3, 2013.

[17] Z. M. Sori, "Accounting information systems (AIS) and knowledge management: a case study," American Journal of scientific research, pp. 36-44, 2009. 